\title{
Effect of lentiviral vector-packaged interleukin-18 gene on the malignant behavior of lung cancer
}

\author{
XIANGQI CHEN ${ }^{1,2^{*}}$, RUI FENG $^{3 *}$, DONGLAN XIONG $^{1 *}$, SHENG YANG $^{3-6}$ and TINGYAN LIN ${ }^{1,2}$ \\ ${ }^{1}$ Teaching and Research Department of Respiratory Medicine, Union Clinical Medical College of Fujian Medical University; \\ Departments of ${ }^{2}$ Respiratory Medicine and ${ }^{3}$ Oncology Medicine, Fujian Medical University Union Hospital; ${ }^{4}$ Teaching and \\ Research Department of Oncology Medicine, Union Clinical Medical College of Fujian Medical University; \\ ${ }^{5}$ Fujian Key Laboratory of Translational Cancer Medicine; ${ }^{6}$ Fujian Medical University \\ Stem Cell Research Institute, Fuzhou, Fujian 350001, P.R. China
}

Received July 13, 2018; Accepted June 27, 2019

DOI: $10.3892 /$ etm.2019.8204

\begin{abstract}
Interleukin-18 (IL-18) is a multifunctional cytokine that exhibits antitumor, anti-infection and immunoregulatory functions. This study aimed to investigate the effects of lentiviral vector-packaged interleukin (IL)-18 gene on the malignant behavior of lung cancer and the potential underlying molecular mechanism of IL-18 anticancer activity. Human lung adenocarcinoma A549 cells transfected with human IL-18 gene-containing lentiviral expression vector were the IL-18 intervention group (group A), cells transfected with the empty lentiviral expression vector were empty vector group (group B), and cells without any intervention were the blank control group (group C). Reverse transcription-quantitative PCR and western blotting were used to determine IL-18 mRNA and protein expression levels. Cell Counting Kit-8, colony-formation, flow cytometry, invasion and wound-healing assays were used to evaluate the malignant behavior of A549 cells transfected with the IL-18 lentiviral vector. The expression levels of the $\mathrm{T}$ helper $(\mathrm{Th}) 1$ cell cytokine interferon- $\gamma($ IFN- $\gamma)$ and the Th 2 cell cytokine IL-4 were tested by ELISA, and western blotting was used to test the expressing of nuclear factor $\kappa \mathrm{B}(\mathrm{NF}-\kappa \mathrm{B})$. The results demonstrated that IL-18 mRNA and protein expression levels in group A were significantly increased compared with groups B and $\mathrm{C}$; the expression levels of IFN- $\gamma$ in group A were higher and the expression levels of IL-4
\end{abstract}

Correspondence to: Professor Sheng Yang, Department of Oncology Medicine, Fujian Medical University Union Hospital, 29 Xinquan Road, Fuzhou, Fujian 350001, P.R. China

E-mail: dryangxh@126.com

Professor Tinyan Lin, Teaching and Research Department of Respiratory Medicine, Union Clinical Medical College of Fujian Medical University, 29 Xinquan Road, Fuzhou, Fujian 350001, P.R. China

E-mail:drlcxhhx@126.com

${ }^{*}$ Contributed equally

Key words: interleukin-18 gene, lentivirus, lung cancer, biological behavior, molecular mechanism in group A were lower compared with those in groups B and C; and the expression of $\mathrm{NF}-\kappa \mathrm{B}$ was increased in the cytoplasm and decreased in the nucleus in group A compared with groups B and C. The data indicated that, compared with the control groups, the IL-18 gene lentiviral expression vector increased the expression of IL-18, diminished A549 cell proliferative ability, enhanced apoptosis, decreased the invasive and metastatic capacities of the cells, promoted the secretion of IFN- $\gamma$, decreased the production of IL-4, reversed the imbalance of Th1/Th2 cell subsets and inhibited the nuclear activation of $\mathrm{NF}-\kappa \mathrm{B}$, which collectively present an anti-lung cancer mechanism and deserve further study.

\section{Introduction}

Currently, lung cancer exhibits the highest incidence and mortality rates among malignant tumors in the world, having caused an estimated 1.6 million deaths worldwide in 2012 (1). Although drug treatments for lung cancer have been developed rapidly, and the level of clinical multidisciplinary integrated treatment has been improved, no breakthrough has yet been achieved in the long-term efficacy of treatment and prognosis (2). Immunotherapy is a novel method for tumor therapy following surgery, radiotherapy and chemotherapy $(3,4)$. Immunotherapy exhibits a unique curative effect in cancer research and clinical practice, which is expected to provide new possibilities for the prevention and treatment of lung cancer (5).

Interleukin (IL)-18 is a multifunctional cytokine that exhibits antitumor, anti-infection and immunoregulatory functions $(6,7)$. Zheng et al (8) observed the apoptosis of melanoma ZD55 cells via adenovirus-packaged IL-18 infection. In 2016, a study by Jia et al (9) revealed that IL-18-607 A/C polymorphism increases the risk of non-small cell lung cancer. In 2017, Timperi et al (10) demonstrated that IL-18R may serve as a biomarker for a minority of functional tumor-infiltrating $\mathrm{CD} 8+\mathrm{T}$ cells in patients with non-small cell lung adenocarcinoma. In 2018, another study demonstrated that IL-18 not only promoted the expansion of natural killer (NK) cells, but also changed their phenotype (11). In the current study, an Annexin V-FITC/PI flow cytometry assay was performed, the results of which revealed the enhanced apoptosis of A549 cells following infection with a lentivirus carrying the hIL-18 gene. 
The aim of the present study was to investigate the effect of transfecting a lentiviral IL-18 gene expression vector into lung adenocarcinoma A549 cells on the malignant biological behavior, such as proliferation, apoptosis, invasion and migration, and to explore the possible underlying mechanisms.

\section{Materials and methods}

Materials. The pGC-LV vector, pHelper 1.0 vector and pHelper 2.0 vector were purchased from Shanghai GeneChem Co., Ltd. Lentiviral plasmids carrying enhanced green fluorescent protein (EGFP) were purchased from Hanbio Biotechnology Co., Ltd. Polybrene, pancreatin, MTT and DMSO were purchased from Sigma-Aldrich; Merck KGaA. RPMI-1640 culture medium was purchased from Gibco; Thermo Fisher Scientific, Inc. Human interferon- $\gamma($ IFN- $\gamma)$ and Human IL-4 ELISA kits were purchased from Santa Cruz Biotechnology, Inc.

Cell culture. The human lung cancer A549 cell line was purchased from Shanghai Cell Resource Center of the Chinese Academy of Sciences (Shanghai, China). The A549 cells were cultured in RPMI-1640 culture medium containing 10\% FBS (HyClone; GE Healthcare Life Sciences) at $37^{\circ} \mathrm{C}$ with $5 \% \mathrm{CO}_{2}$. The cells were digested and passaged every 2-3 days. Cells in the exponential phase of growth were used for subsequent experiments.

Construction and grouping of the IL-18 gene lentiviral expression vector in A549 cells. A549 cell suspensions were seeded into six-well plates at a density of $4 \times 10^{5}$ cells/well. The following day, DMEM (HyClone; GE Healthcare Life Sciences) with 10\% v/v FBS (complete medium) was removed and replaced with virus concentrated liquid (Shanghai GeneChem Co., Ltd.) containing the IL-18 gene vector with green fluorescence protein (GFP) (Shanghai GeneChem Co., Ltd.) to detect transfection efficacy. Polybrene reagent (Shanghai GeneChem Co., Ltd.) was diluted to a final concentration of $5 \mu \mathrm{g} / \mathrm{ml}$. Multiplicity of infection (MOI) values (1, 2, 5, 10, 30 and 50) were then tested in A549 cells. A total of $4 \times 10^{6}$ lentivral particles were used for transfection and the optimal MOI value was 10 in the present study. At this value, the efficiency of infection reached $80 \% 3$ days post-infection. After swirling the plate gently to mix cells, the plate was placed in an incubator with $50 \mathrm{ml} / 1 \mathrm{CO}_{2}$ at $37^{\circ} \mathrm{C}$ for $24 \mathrm{~h}$. After $24 \mathrm{~h}$, the medium was removed and replaced by complete medium. Three days post-transfection, GFP expression was observed as the lentivirus was integrated into the A549 cell genome, in five randomly-selected fields using a fluorescence microscope (magnification, x200). Cells with a transfection efficiency $>80 \%$ on day 3 were selected for subsequent analysis. Lentiviruses were purchased from Shanghai GeneChem Co., Ltd. Human lung adenocarcinoma A549 cells transfected with the hIL-18 lentiviral expression vector were deemed the IL-18 intervention group (group A). Cells transfected with the empty lentiviral expression vector were deemed the lentiviral empty vector group (group B) and cells without any intervention were called the blank control group (group C).

Determination of IL-18 mRNA expression by reverse transcription-quantitative PCR. Total RNA was extracted from A549 cells using TRIzol ${ }^{\circledR}$ reagent (Invitrogen; Thermo Fisher Scientific, Inc.). Total RNA ( $1 \mu \mathrm{g})$ was reverse transcribed to cDNA using a High Capacity cDNA Reverse Transcription kit (Thermo Fisher Scientific, Inc.) in accordance with the manufacturer's protocol. qPCR was performed using the SYBR Green Reverse Transcription PCR Master mix (Takara Biotechnology Co., Ltd.) on an Applied Biosystems 7300 plus reverse transcription PCR system (Thermo Fisher Scientific, Inc.). The sequences were as follows: IL-18 forward, 5'-ACTGTACAACCGCAGTAATAC-3' and reverse, 5'-AGTGAACATTACAGATTTATCCC-3' (product size, $434 \mathrm{bp}$ ); $\beta$-actin forward, 5'-CTCCATCCTGGCCTCDCT GT-3' and reverse, 5'-GCTGTCACCTTCACCGTTCC-3'. The following thermocycling conditions were used for qPCR: Initial denaturation at $95^{\circ} \mathrm{C}$ for $30 \mathrm{sec}$; 40 cycles of $95^{\circ} \mathrm{C}$ for $5 \mathrm{sec}$ and $60^{\circ} \mathrm{C}$ for $30 \mathrm{sec}$. Expression levels were quantified using the $2^{-\Delta \Delta \mathrm{Cq}}$ method (12) and $\beta$-actin was used as an internal reference gene.

Cell Counting Kit-8 (CCK-8) assay. At the exponential growth phase of each group, A549 cells were seeded into 96-well plates at $1 \times 10^{4}$ cells/well. Then the plates with cells were incubated at $37^{\circ} \mathrm{C}$ with $5 \% \mathrm{CO}_{2}$ for $0,24,48,72$ or 96 h. CCK-8 reagent (10 $\mu \mathrm{l}$; Beyotime Institute of Biotechnology) was then added to each well. Cells were incubated at $37^{\circ} \mathrm{C}$ for a further $2 \mathrm{~h}$, after which the optical density (OD) values were measured at $450 \mathrm{~nm}$ using a microplate reader (BioTek Instruments Inc.). The mean value of 6 wells was calculated as the final optical density (OD) value. The cell proliferation curve was plotted as OD over time. The growth inhibition rate (IR) was calculated as: IR $(\%)=1-(\mathrm{OD}$ value of group A-OD background)/(OD value of group C-OD background) $\mathrm{x} 100 \%$.

Colony-formation assay. Cells at the exponential growth phase from each group were inoculated into 24 -well plates at 200 cells/well in triplicate. The cells were then incubated at $37^{\circ} \mathrm{C}$ with $5 \% \mathrm{CO}_{2}$ for 2 weeks. The incubation was terminated when visible clones formed on the plates. The clones were washed with PBS. Cells were fixed with $4 \%$ paraformaldehyde at room temperature for $15 \mathrm{~min}$ and stained with $0.4 \%$ crystal violet at room temperature for $10 \mathrm{~min}$. The colonies with $>50$ cells were counted in each well under a WTDS- 1 inverted microscope (magnification, x40; Olympus Corporation).

Flow cytometry. A549 cells $\left(1 \times 10^{6}\right.$ cells/well) were cultured at $37^{\circ} \mathrm{C}$ for $96 \mathrm{~h}$. Cell apoptosis was then assessed using a FITC apoptosis detection kit (Oncogene Research Products) according to the manufacturer's protocol. Cells were subsequently harvested and washed with ice-cold PBS. Annexin V-FITC and propidium iodide (PI) dye (10 $\mu \mathrm{l}$ each) were then added and mixed. The mixture was incubated for $15 \mathrm{~min}$ at room temperature and the stained cells were analyzed via flow cytometry (FACSCanto; BD Biosciences). Data were analyzed using the FlowJo software package (version 10.0.7; Tree Star, Inc.).

Transwell invasion assay. The three groups of cells $\left(5 \times 10^{5}\right)$ were resuspended in serum-free $200 \mu 1$ RPMI-1640 medium and plated into the upper chamber ( $8 \mathrm{~mm}$; Corning Inc.) of Matrigel-coated (BD Biosciences) 24-well transwell chambers (Corning Inc.). The lower chambers were plated with $600 \mu \mathrm{l}$ RPMI-1640 medium supplemented with 10\% FBS. After incubating at $37^{\circ} \mathrm{C}$ for $48 \mathrm{~h}$, non-migrated cells were removed with cotton swabs. Migrated cells were fixed with $4 \%$ paraformaldehyde at room temperature for $15 \mathrm{~min}$ and stained with 
A
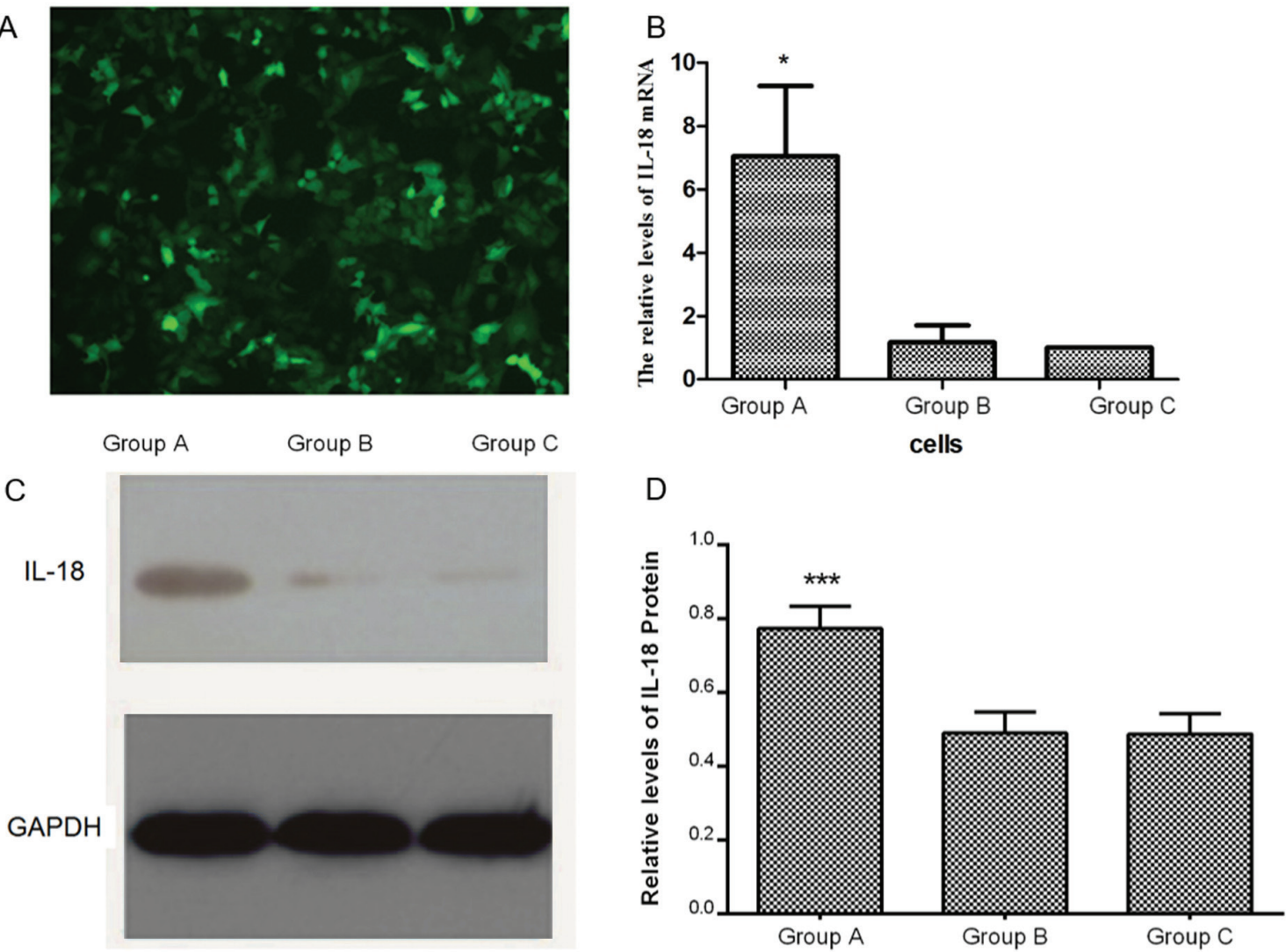

Figure 1. IL-18 protein expression in A549 cells following lentiviral vector transfection. (A) Representative image of A549 cells transfected successfully with a lentiviral expression vector carrying hIL-18 gene and enhanced green fluorescent protein. magnification, x20. (B) Expression of IL-18 mRNA in the three groups was determined by reverse transcription-quantitative PCR. (C) Protein expression of IL-18 in the three groups detected by western blotting. (D) Quantification of IL-18 protein expression in the three groups. IL-18 expression levels in group A were significantly higher compared with those in groups B and C. ${ }^{*} \mathrm{P}<0.05$ and ${ }^{* * *} \mathrm{P}<0.01$ vs. groups B and C. Group A, A549 cells transfected with hIL-18 lentiviral vector; group B, A549 cells transfected with an empty vector; group C, untransfected A549 cells. IL-18, interleukin-18; hIL-18, human IL-18.

$0.1 \%$ crystal violet for $10 \mathrm{~min}$. Stained cells were counted from five independent fields using an inverted fluorescent microscope (magnification, x400; Olympus IX53; Olympus Corporation).

Wound healing assay. The three groups of cells ( $5 \times 10^{5}$ cells/well) were seeded into 6-well plates. After reaching 90\% confluence, three scratches were created in each well using a $200 \mu \mathrm{l}$ sterile pipette tip. The cells were then washed twice with PBS and incubated in medium supplemented without FBS for at $37^{\circ} \mathrm{C}$ $48 \mathrm{~h}$. To observe the migration of cells, images of the wells were obtained at 0,24 and $48 \mathrm{~h}$ in three randomly selected microscopic fields (magnification, x400; Olympus Corporation). The distance was measured using ImageJ software (National Institutes of Health) and the healing rate was calculated.

Detection of Thelper (Th)1 and Th2 cell cytokine expression by ELISA. Following $96 \mathrm{~h}$ of cell culture at $37^{\circ} \mathrm{C}$, supernatants were harvested and IFN- $\gamma$ (cat. no. DIF50) or IL-4 (cat. no. D4050) levels were measured via ELISA (R\&D Systems) in accordance with the manufacturer's protocol.

Western blot analysis. Protein from the three cell groups was isolated following incubation at $37^{\circ} \mathrm{C}$ for $96 \mathrm{~h}$ using RIPA assay lysis buffer (Beyotime Institute of Biotechnology) and quantified using a bicinchoninic acid kit (Beyotime Institute of Biotechnology). Proteins (50 $\mu \mathrm{g}$ per lane) were separated via
SDS-PAGE (10\% gel) and transferred onto a PVDF membrane. The membrane was then blocked with $5 \%$ non-fat dry milk at $4^{\circ} \mathrm{C}$ for $1 \mathrm{~h}$. Primary antibodies against IL-18 (1:1,000; cat. no. ab207324), NF-кBp65 (1:1,000; cat. no. ab16502) and GAPDH (1:1,000; cat. no. ab181602) were added, and the mixture was incubated overnight at $4^{\circ} \mathrm{C}$ with gentle agitation. Following three washes with Tris-buffered saline with Tween, horseradish peroxidase-conjugated goat anti-rabbit secondary antibodies (1:5,000; cat. no. ab97051; Abcam) was added and incubated at room temperature for $2 \mathrm{~h}$. Protein bands were detected using the Super Signal West Pico Chemiluminescent substrate (Thermo Fisher Scientific, Inc.). and protein expression was quantified using Image J 1.43 software (National Institutes of Health).

Statistical analysis. Data were analyzed by SPSS version 19.0 (IBM Corp.) statistical software. Quantitative data are expressed as the mean \pm standard deviation. One-way ANOVA was used to compare different groups, followed by the least significant difference (for data with homogeneity of variance) or Dunnett's T3 (for data with heterogeneity of variance) post hoc test. $\mathrm{P}<0.05$ was considered to indicate a statistically significant difference.

\section{Results}

IL-18 protein expression in A549 cells following lentiviral vector transfection. A hIL-18 gene lentiviral vector carrying 

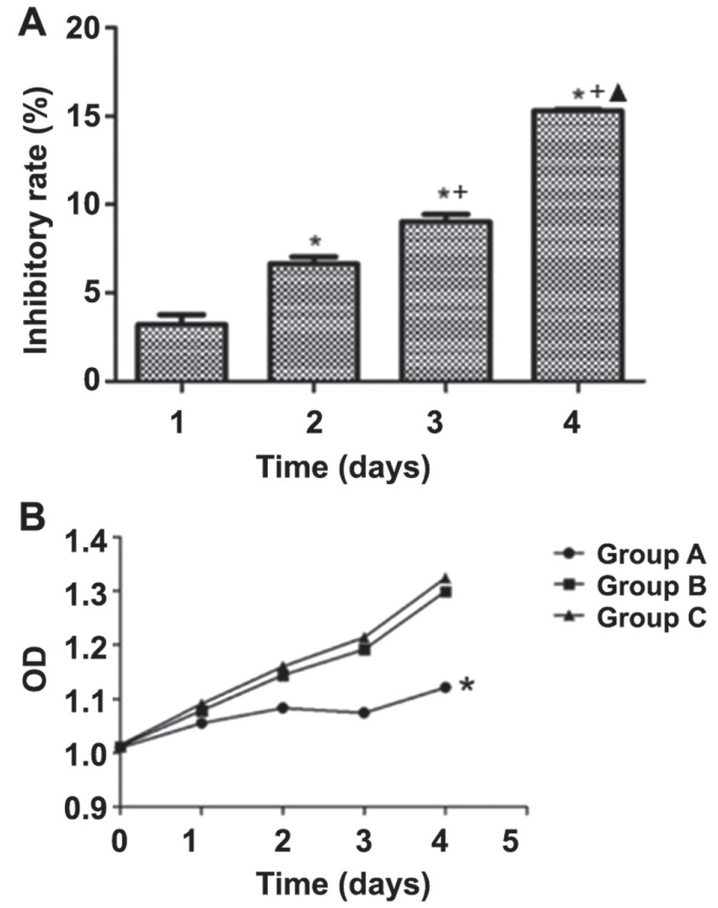

Figure 2. Influence of hIL-18 lentiviral vector transfection on A549 cell proliferation. (A) Inhibitory rate of group A cells at different days. (B) The growth curves of the three groups of cells revealed that there was no significant difference between groups $\mathrm{B}$ and $\mathrm{C}$, indicating that the empty lentivirus expression vector had no effect on the proliferation of A549 cells. ${ }^{*} \mathrm{P}<0.05$ vs day $1 ;{ }^{+} \mathrm{P}<0.05$ vs. day $2 ;{ }^{\wedge} \mathrm{P}<0.05$ vs. day 3 in (A). ${ }^{*} \mathrm{P}<0.05$ vs. groups $\mathrm{B}$ and $\mathrm{C}$ in (B). The data are presented as the mean \pm SD $(n=6)$. Group A, A549 cells transfected with hIL-18 lentiviral vector; group B, A549 cells transfected with an empty vector; group C, untransfected A549 cells. hIL-18, human interleukin-18; OD, optical density.

EGFP was transfected into human lung adenocarcinoma A549 cells, which resulted in green fluorescence (Fig. 1A). The results of the RT-qPCR assay demonstrated that the expression of IL-18 mRNA in group A was significantly higher compared with that in groups $\mathrm{B}$ and $\mathrm{C}(\mathrm{P}<0.05)$, whereas there was no significant difference between groups B and C (Fig. 1B). Western blotting analysis revealed that the expression and the quantification of IL-18 in group A was significantly higher than in groups $\mathrm{B}$ and $\mathrm{C}(\mathrm{P}<0.001$; Fig. $1 \mathrm{C}$ and $\mathrm{D})$, which was consistent with the results of the RT-qPCR analysis.

Effects of IL-18 overexpression on A549 cell proliferation. The OD values of the three groups at day 0 , day 1, day 2, day 3 and day 4 following transfection with the hIL-18 lentiviral vector were measured by CCK-8 assay (Fig. 2B). At day 1, no significant differences in cell proliferation were observed among groups A, B and C. At day 2, day 3 and day 4, the proliferation in group A was significantly lower compared with that in groups B and $\mathrm{C}(\mathrm{P}<0.05)$, whereas no significant differences were observed between groups $\mathrm{B}$ and $\mathrm{C}(\mathrm{P}>0.05)$. According to the data, the proliferation rate of the cells in group A was significantly slower compared with that of the control groups. The inhibition ratios for group A at day 1, day 2, day 3 and day 4 were $3.210 \pm 0.565,6.640 \pm 0.398,9.030 \pm 0.407$ and $15.307 \pm 0.081 \%$, respectively, suggesting that IL-18 may inhibit the proliferation of A549 cells in a time-dependent manner (Fig. 2A). However, no significant differences were observed between groups B and

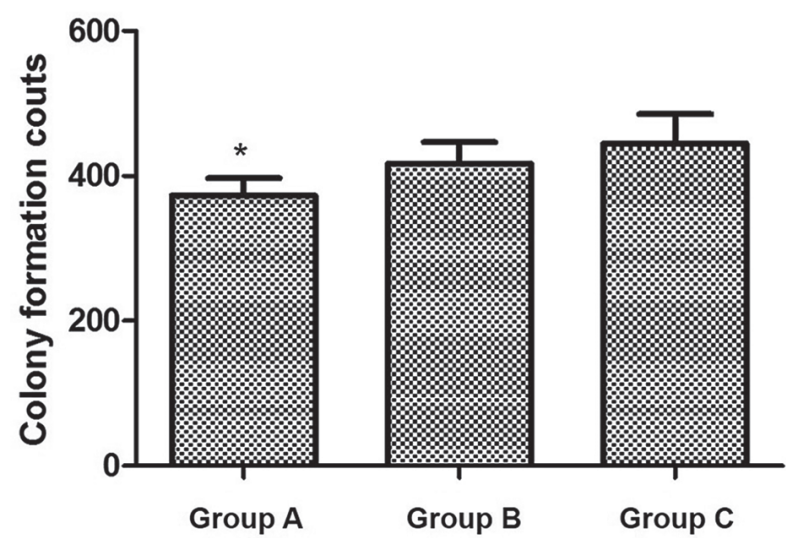

Figure 3. Colony-formation activity of A549 cells following hIL-18 lentiviral vector transfection. Cell colony-formation counts of the three groups. ${ }^{*} \mathrm{P}<0.05$ vs. groups B and C. Group A, A549 cells transfected with hIL-18 lentiviral vector; group B, A549 cells transfected with an empty vector; group C, untransfected A549 cells. hIL-18, human interleukin-18.

$\mathrm{C}$, which indicated that the empty lentivirus expression vector had no effects on the proliferation of A549 cells (Fig. 2B).

Colony formation in A549 cells following hIL-18 lentiviral vector transfection. A total of 200 cells were seeded into a 24-well plate and incubated for 2 weeks. The colony counts in groups A, B and C were $373 \pm 24.02,417 \pm 29.51$ and $445 \pm 40.85$, respectively; the colony formation in group A was significantly decreased compared with that in groups $\mathrm{B}$ and $\mathrm{C}(\mathrm{P}<0.05)$, which indicated that the cells with IL-18 intervention had lower proliferating capacity (Fig. 3). The difference between groups $\mathrm{B}$ and $\mathrm{C}$ was not significant.

Induction of apoptosis in A549 cells following hIL-18 lentiviral vector transfection. Cells from each group were cultured for $96 \mathrm{~h}$, and apoptotic rates were determined by flow cytometry using the Annexin V-FITC/PI staining method. The apoptotic rates of groups $\mathrm{A}, \mathrm{B}$ and $\mathrm{C}$ were $9.10 \pm 0.37,1.57 \pm 0.21$ and $1.37 \pm 0.15 \%$, respectively, with that of group A being significantly higher than those in the control groups $(\mathrm{P}<0.05)$, whereas no significant difference was observed between groups B and C (Fig. 4).

Invasive capacity of A549 cells following hIL-18 lentiviral vector transfection. Cells in each group were cultured for $48 \mathrm{~h}$, and the invasive capacities were determined by a Transwell assay. The mean number of cells permeating the membrane in groups A, B and C were 476.0 $\pm 55.7,824.3 \pm 64.6$ and 988.7 \pm 44.1 respectively. The invading cells of group A were significantly fewer than those in groups $\mathrm{B}$ and $\mathrm{C}(\mathrm{P}<0.05)$, whereas no significant difference was observed between groups B and C (Fig. 5).

Migratory capacity of A549 cells following hIL-18 lentiviral vector transfection. A total of $48 \mathrm{~h}$ after scratching, the wound-healing rate of group A was $65.64 \%$. The wound healing rates of $\mathrm{B}$ and $\mathrm{C}$ were at $100.00 \%$, which was significant when compared with the results of group A (all $\mathrm{P}<0.05$; Fig. 6).

Changes in Th cell cytokine production by A549 cells following hIL-18 lentiviral vector transfection. The ELISA 

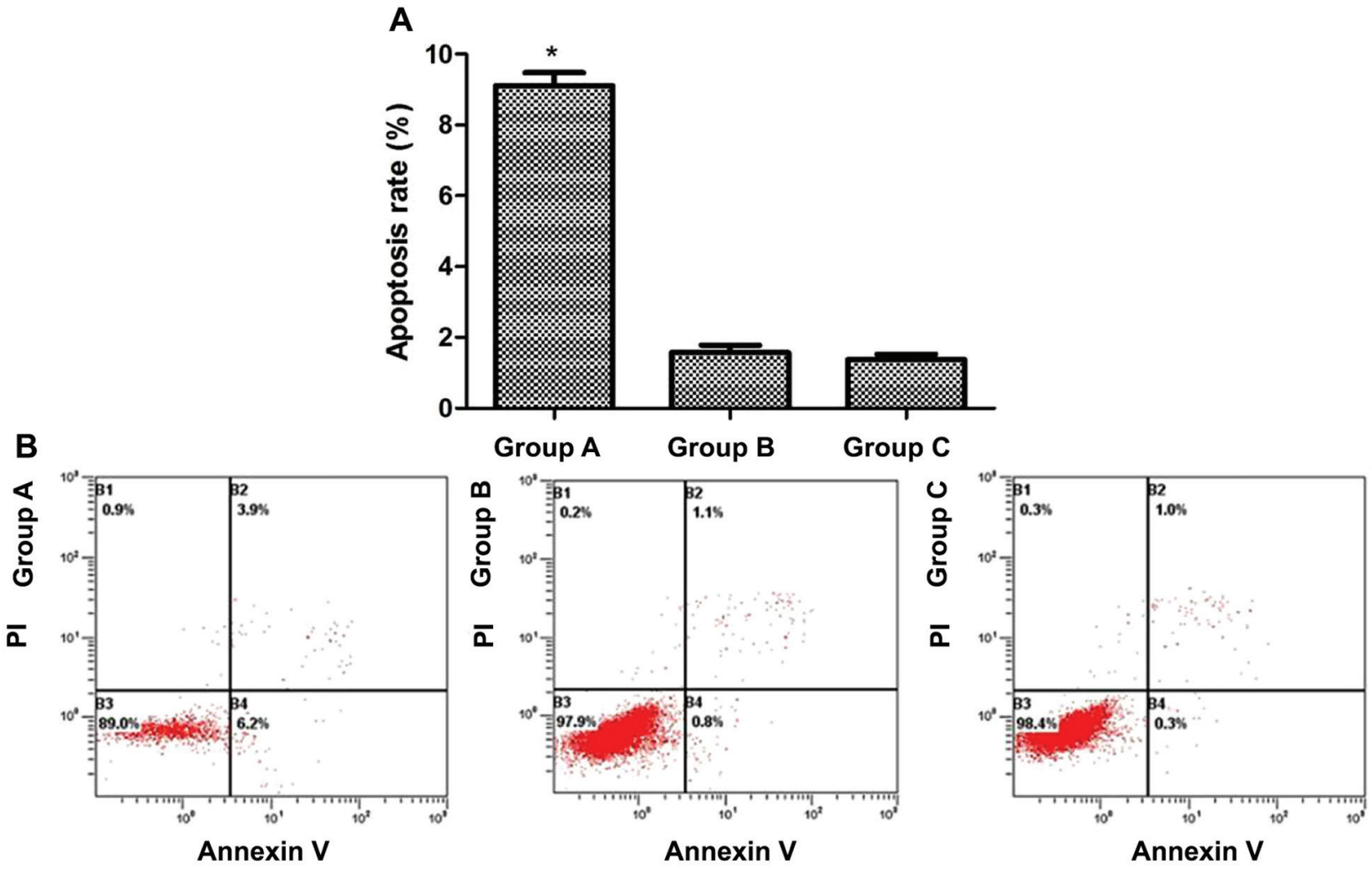

Figure 4. Induction of apoptosis in A549 cells following hIL-18 lentiviral vector transfection. (A) The apoptotic rate and (B) the scatter diagrams of apoptosis detection in the three groups of cells $96 \mathrm{~h}$ following transfection. Apoptosis was significantly higher in group A compared with that in groups B and C. The data are presented as the mean $\pm \mathrm{SD}(\mathrm{n}=3)$. " $\mathrm{P}<0.05$ vs. groups B and C. Group A, A549 cells transfected with hIL-18 lentiviral vector; group B, A549 cells transfected with an empty vector; group C, untransfected A549 cells. hIL-18, human interleukin-18; PI, propidium iodide.

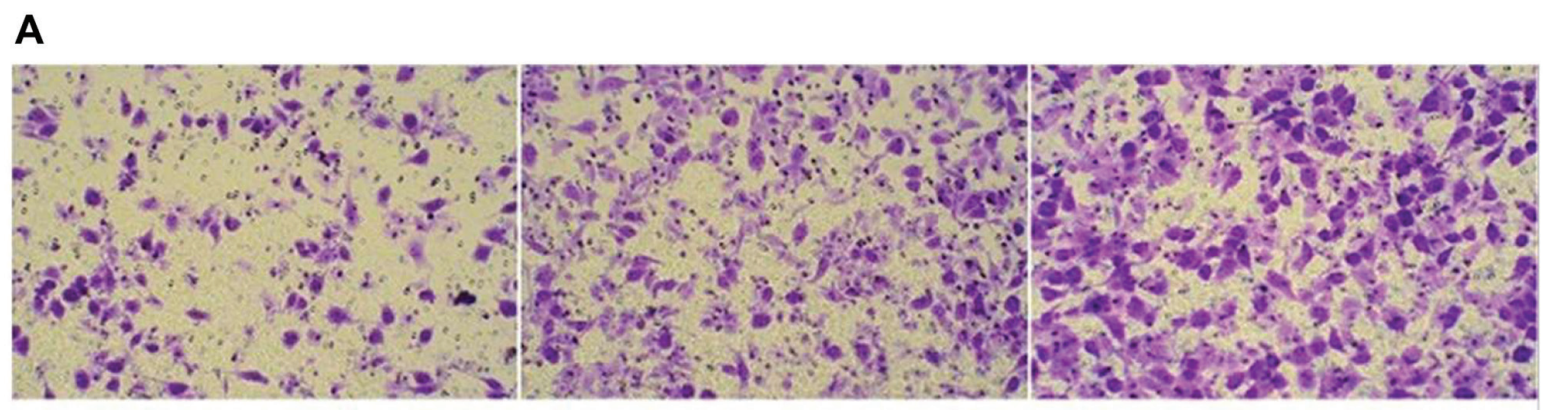

Group A

Group B

Group C

\section{B}

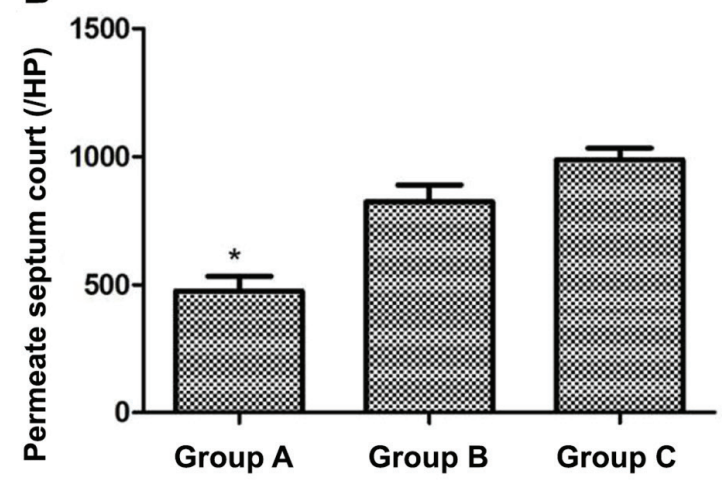

Figure 5. Invasion ability of A549 cells following hIL-18 lentiviral vector transfection (A) Invasive capacity of A549 cells following hIL-18 lentiviral vector transfection (magnification, $\mathrm{x} 400$ ). (B) The mean number of cells permeating the membrane in the three groups demonstrated that the invasive capacity of cells in group A was significantly decreased compared with that in groups B and C. The data are presented as the mean \pm SD $(n=3)$. " $P<0.05$ vs. groups B and C. Group A, A549 cells transfected with hIL-18 lentiviral vector; group B, A549 cells transfected with an empty vector; group C, untransfected A549 cells. hIL-18, human interleukin-18. 
A
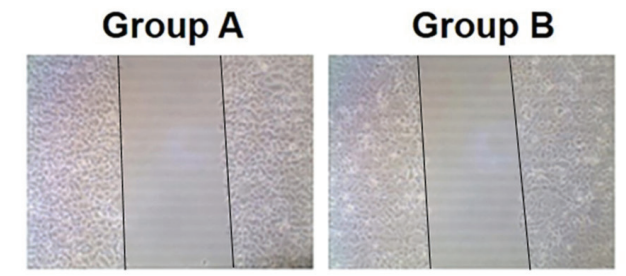

Group C

$\mathrm{Oh}$
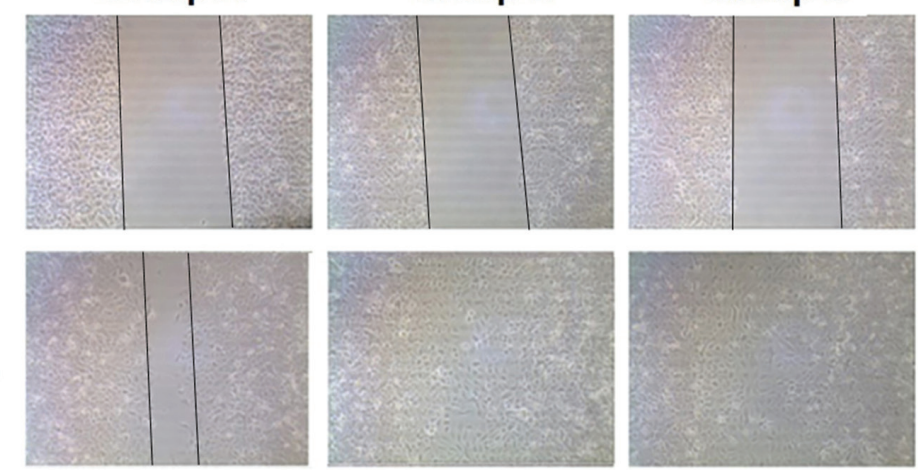

B

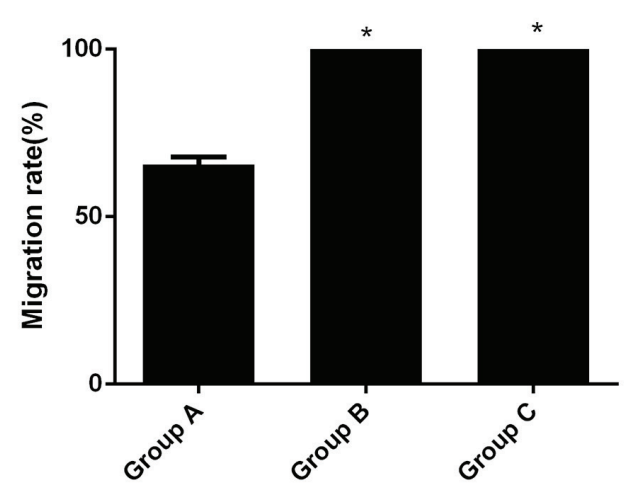

Figure 6. Migratory capacity of A549 cells following hIL-18 lentiviral vector transfection (x40). (A) Microscopic visualization of cell migration in groups A, $\mathrm{B}$ and $\mathrm{C}$ at 0 and $48 \mathrm{~h}$. (B) At $48 \mathrm{~h}$, the cells of group A exhibited limited migration, whereas in groups B and C migration was obvious; the cell migratory capacity of group A was markedly decreased. ${ }^{*} \mathrm{P}<0.05$ vs. groups B and C. Group A, A549 cells transfected with hIL-18 lentiviral vector; group B, A549 cells transfected with an empty vector; group C, untransfected A549 cells. hIL-18, human interleukin-18.

B

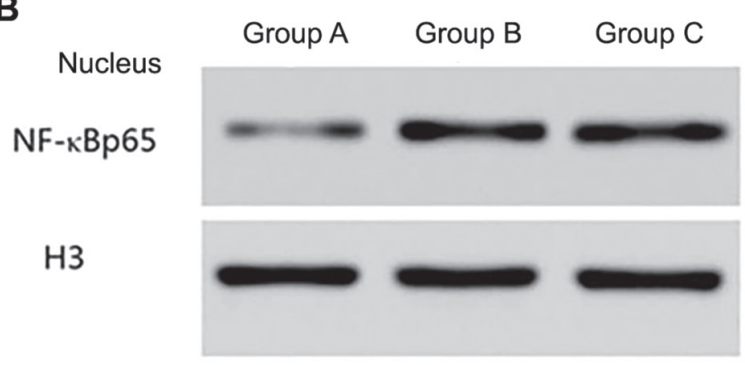

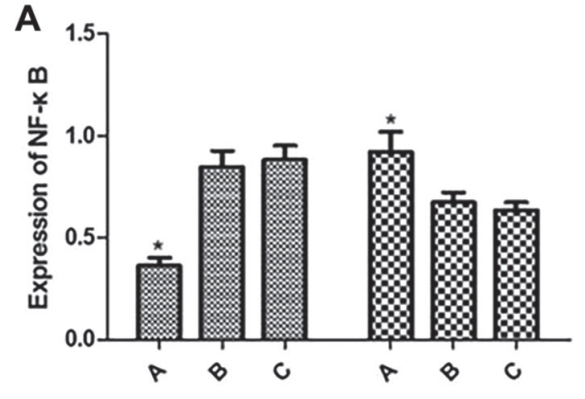

$$
\begin{aligned}
& \text { Nucleus } \\
& \text { A Cytoplasm } \\
& \text { A - Group A } \\
& \text { B - Group B } \\
& \text { C - Group C }
\end{aligned}
$$

Figure 7. Nuclear and cytoplasmic expression of NF- $\kappa$ B in A549 cells following hIL-18 lentiviral vector transfection. (A) The expression of NF- $\kappa$ B presented as a bar graph and (B) presented via western blotting in the nucleus and cytoplasm. In group A, NF- $\mathrm{B}$ expression was decreased in the nucleus and increased in the cytoplasm compared with groups B and C. " P<0.05 vs. groups B and C. Group A, A549 cells transfected with hIL-18 lentiviral vector; group B, A549 cells transfected with an empty vector; group C, untransfected A549 cells. hIL-18, human interleukin-18, NF- $\kappa$ B, nuclear factor $\kappa$ B.

assay results (Table I) demonstrated that IFN- $\gamma$ expression was significantly higher and IL-4 expression was significantly lower in group A than in the control groups (all $\mathrm{P}<0.05$ ), and the IFN- $\gamma /$ IL- 4 ratio in group A was significantly higher than in groups $\mathrm{B}$ and $\mathrm{C}(\mathrm{P}<0.05)$.
Nuclear and cytoplasmic NF- $\kappa B$ expression in A549 cells following hIL-18 lentiviral vector transfection. Western blot analysis detected the expression of NF- $\mathrm{B}$ in the cytoplasm and nucleus of the cells in groups A, B and C (Fig. 7). In group A, $\mathrm{NF}-\kappa \mathrm{B}$ expression was decreased in the nucleus and increased 
Table I. ELISA detection of IFN- $\gamma$ and IL-4 in the three groups of cells and the IFN- $\gamma / \mathrm{IL}-4$ ratio (mean $\pm \mathrm{SD} ; n=6$ ).

\begin{tabular}{lccc}
\hline Group & IFN- $\gamma$ & IL-4 & IFN- $\gamma /$ IL-4 \\
\hline A & $0.52 \pm 0.02^{\mathrm{a}}$ & $0.70 \pm 0.02^{\mathrm{a}}$ & $0.736 \pm 0.028^{\mathrm{a}}$ \\
B & $0.35 \pm 0.03$ & $0.78 \pm 0.02$ & $0.448 \pm 0.040$ \\
C & $0.33 \pm 0.02$ & $0.81 \pm 0.02$ & $0.403 \pm 0.031$ \\
\hline
\end{tabular}

${ }^{\mathrm{a}} \mathrm{P}<0.05$ vs. groups B and C. Group A, A549 cells transfected with human interleukin-18 lentiviral vector; group B, A549 cells transfected with an empty vector; group C, untransfected A549 cells. IFN- $\gamma$, interferon $\gamma$; IL-4, interleukin 4 .

in the cytoplasm compared with groups B and C. No significant differences were observed between groups $\mathrm{B}$ and $\mathrm{C}$ in the cytoplasm and nucleus.

\section{Discussion}

The results of this study demonstrated that cytokine IL-18 was stably expressed following transfection with a lentiviral vector-packaged hIL-18 gene, which led to decreased proliferation of human lung cancer A546 cells, increased apoptosis and impaired invasion and migration. The hIL-18 lentivirus reverted the ratio of Th1/Th2 subsets by enhancing IFN- $\gamma$ secretion by Th1 cells and reducing IL- 4 secretion by Th2 cells to maintain the balance between the Th1 and Th2 subsets. In addition, hIL-18 lentivirus inhibited nuclear translocation of NF- $\mathrm{kB}$ to proactively exert its anticancer activity.

Lentiviral vectors exhibit multiple merits, such as the ability to carry a large fragment of the target gene, minimized induction of the host immune response, the ability to infect both dividing and non-dividing cells, and stable integration into the genome of target cells (13). Therefore, a lentiviral vector was selected for hIL-18 gene delivery in the current study, to infect human lung cancer A546 cell line in order to thoroughly and systematically investigate the anticancer function of IL-18 and its underlying mechanism.

Immunological studies have demonstrated that Th1 and Th2 cells are dynamically balanced under healthy conditions, and the drift of Th1 to Th2 subset may result in immune suppression, which severely interferes with the anticancer function of immune surveillance. The Th2 subset dominance in tumor patients was first reported by Yamamura et al (14) in 1993 and confirmed by Asselin et al (15) in 1998, who reported the Th2-dominant model in lung cancer cell lines. Furthermore, a clinical trial by Chechlińska et al (16) demonstrated a Th2 drift in patients with lung cancer. IL-18 may therefore enhance anticancer function via positive feedback and maintain the balance of Th1 and Th2 subsets. Yamashita et al (17) and Yamanaka and Xanthopoulos (18) demonstrated that IL-18 stimulates Th1 and NK cells to secrete IFN- $\gamma$ and promote immune response mediated by Th1 cells.

The association between IL-18 and tumor development has been confirmed, although its antitumor function remains controversial, particularly the effects of IL-18 on metastasis $(19,20)$. $\mathrm{Xu}$ et al (21) demonstrated that IL-18 may upregulate the expression of Fas ligand in colorectal cancer cells to facilitate immune surveillance evasion. Therefore, the biological role of IL-18 requires further investigation.

The results of the present study indicated that the hIL-18 lentiviral vector infected A549 cells to significantly alter the invasion and migration of these cells, as revealed by the reduced number of invading cells and decreased wound-healing rate in the in vitro assays.

$\mathrm{NF}-\mathrm{\kappa B}$, a dimer composed of subunits p50 and p65, is a cytokine that regulates the expression of multiple cytokines (22) NF- $\mathrm{kB}$ is shared by multiple signal transduction pathways and is involved in various biological processes, such as cellular immune response, stress response, cell proliferation and apoptosis (23). The inactive form of NF- $\mathrm{kB}$ is present in the cytoplasm in a complex with the inhibitory protein IкB (24). Subsequently, the expression of the downstream genes is regulated to exert their biological functions. The role of NF- $\mathrm{KB}$ in the development of lung cancer has been extensively investigated. Yang et al (25) revealed that activated NF- $\mathrm{KB}$ dysregulates the cell cycle and suppresses apoptosis to promote chemoresistance and tumorigenesis in lung cancer cells. Activated NF- $\mathrm{KB}$ also promotes the invasion and metastasis of primary lung adenocarcinoma by upregulating the expression of matrix metalloproteinase (MMP)-2 and MMP9 expression (26). IL-18 has been reported to inhibit airway inflammation of bronchial asthma through the inhibition of NF- $\kappa B$ (27). The mechanism of apoptosis in cervical cancer cells induced by mitomycin involves not only caspase- 8 and caspase-3-dependent Fas/Fas ligand pathway, but also IL-18 expression and NF- $\mathrm{KB}$ activation (28). In the current study, the expression of nuclear NF- $\mathrm{kB}$ was significantly decreased in A549 cells infected with the hIL-18 lentivirus compared with the control groups, whereas the expression of cytoplasmic NF- $\mathrm{KB}$ was significantly increased, which indicated that abnormal proliferation, apoptosis, invasion and migration of A549 cells may be associated with a defect in the NF- $\mathrm{\kappa B}$ pathway.

The results of the present study also demonstrated that IL-18 exhibited an effect in inhibiting the proliferation and invasion of lung cancer cells. The underlying mechanism and potential clinical applications require further study. Clinical trial phase I of IL-18 therapy was conducted by Robertson et al (29) in 19 cancer patients (including 10 myeloma and nine kidney cancer cases). Clinical trial phase II of IL-18 therapy was conducted in non-treated metastatic myeloma patients by Tarhini et al (30). The two trials demonstrated that IL-18 treatment exhibited high tolerance and biological efficacy in cancer treatment. Therefore, IL-18 may be a promising option for future clinical therapy, with increased efficacy in cancer treatment, ideal long-term effects and prolonged survival of the patients.

\section{Acknowledgements}

Not applicable.

\section{Funding}

The present study was supported by grants from the Natural Science Foundation of Fujian Province (grant no. 2011J01170), Nursery Fund of Fujian Medical University (grant 
no. 2010MP034) and Science Technology Innovation Joint Project Foundation of Fujian Province (grant no. 2016Y9028).

\section{Availability of data and materials}

All data generated or analyzed during the present study are included in this published article.

\section{Authors' contributions}

XC, RF, DX, SY and TL designed the experiments, and RF and DX performed them. RF and DX analyzed and interpreted the data. XC wrote the manuscript and SY and TL revised the manuscript. All authors have read and approved the final manuscript.

\section{Ethics approval and consent to participate}

Not applicable.

\section{Patient consent for publication}

Not applicable.

\section{Competing interests}

The authors declare that they have no competing interests.

\section{References}

1. Schild SE and Vokes EE: Pathways to improving combined modality therapy for stage III nonsmall-cell lung cancer. Ann Oncol 27: 590-599, 2016.

2. Fiala O, Šorejs O, Pešek M and Fínek J: Immunotherapy in the treatment of lung cancer. Klin Onkol 30 (Supplementum3): 22-31, 2017 (In Czech).

3. Hontscha C, Borck Y, Zhou H, Messmer D and Schmidt-Wolf IG: Clinical trials on CIK cells: First report of the international registry on CIK cells (IRCC). J Cancer Res Clin Oncol 137: 305-310, 2011.

4. Dougan M and Dranoff G: Immune therapy for cancer. Annu Rev Immunol 27: 83-117, 2009.

5. Li R, Wang C, Liu L, Du C, Cao S, Yu J, Wang SE, Hao X, Ren X and $\mathrm{Li} \mathrm{H}$ : Autologous cytokine-induced killer cell immunotherapy in lung cancer: A phase II clinical study. Cancer Immuno Immunother 61: 2125-2133, 2012.

6. Tian H, Shi G, Yang G, Zhang J, Li Y, Du T, Wang J, Xu F, Cheng L, Zhang X, et al: Cellular immunotherapy using irradiated lung cancer cell vaccine co-expressing GM-CSF and IL-18 can induce significant antitumor effects. BMC Cancer 14: 48, 2014.

7. Tse BW, Russell PJ, Lochner M, Förster I and Power CA: IL-18 inhibits growth of murine orthotopic prostate carcinomas via both adaptive and innate immune mechanisms. PLoS One 6: e24241, 2011.

8. Zheng JN, Pei DS, Mao LJ, Liu XY, Sun FH, Zhang BF, Liu YQ, Liu JJ, Li W and Han D: Oncolytic adenovirus expressing interleukin-18 induces significant antitumor effects against melanoma in mice through inhibition of angiogenesis. Cancer Gene Ther 17: 28-36, 2010.

9. Jia Y, Zang A, Jiao S, Chen S and Yan F: The interleukin-18 gene promoter-607 A/C polymorphism contributes to non-small-cell lung cancer risk in a Chinese population. Onco Targets Ther 9: $1715-1719,2016$.

10. Timperi E, Focaccetti C, Gallerano D, Panetta M, Spada S, Gallo E, Visca P, Venuta F, Diso D, Prelaj A, et al: IL-18 receptor marks functional CD8+ T cells in non-small cell lung cancer. Oncoimmunology 6: e1328337, 2017.

11. Senju H, Kumagai A, Nakamura Y, Yamaguchi H, Nakatomi K, Fukami S, Shiraishi K, Harada Y, Nakamura M, Okamura H, et al: Effect of IL-18 on the expansion and phenotype of human natural killer cells: Application to cancer immunotherapy. Int J Biol Sci 14: 331-340, 2018
12. Livak KJ and Schmittgen TD: Analysis of relative gene expression data using real-time quantitative PCR and the 2(-Delta Delta C(T)) method. Methods 25: 402-408, 2001

13. Yoshimitsu M, Sato T, Tao K, Walia JS, Rasaiah VI, Sleep GT, Murray GJ, Poeppl AG, Underwood J, West L, et al: Bioluminescent imaging of a marking transgene and correction of Fabry mice by neonatal injection of recombinant lentiviral vectors. Proc Natl Acad Sci USA 101: 16909-16914, 2004.

14. Yamamura M, Modlin RL, Ohmen JD and Moy RL: Local expression of antiinflammatory cytokines in cancer. J Clin Invest 91: 1005-1010, 1993.

15. Asselin S, Conjeaud H, Minty A, Fradelizi D and Breban M: Stable polarization of peripheral blood T cells towards type 1 or type 2 phenotype after polyclonal activation. Eur J Immunol 28: 532-539, 1998.

16. Chechlińska M, Duma A, Swierkowska K, Kamińska J and Steffen J: Sera of lung cancer patients affect the release of Th1, Th2 and monocyte-derived cytokines, and the expression of IL-2Ralpha by normal, stimulated mononuclear cells. Cell Mol Biol Lett 9: 69-81, 2004.

17. Yamashita K, Iwasaki T, Tsujimura T, Sugihara A, Yamada N, Ueda H, Okamura H, Futani H, Maruo S and Terada N: Interleukin-18 inhibits lodging and subsequent growth of human multiple myeloma cells in the bone marrow. Oncol Rep 9: 1237-1244, 2002.

18. Yamanaka R and Xanthopoulos KG: Induction of antigen-specific immune responses against malignant brain tumors by intramuscular injection of sindbis DNA encoding gp100 and IL-18. DNA Cell Biol 24: 317-324, 2005.

19. Park S, Cheon S and Cho D: The dual effects of interleukin-18 in tumor progression. Cell Mol Immunol 4: 329-335, 2007.

20. Nakamura Y, Yamada N, Ohyama H, Nakasho K, Nishizawa Y, Okamoto T, Futani H, Yoshiya S, Okamura $\mathrm{H}$ and Terada $\mathrm{N}$ : Effect of interleukin-18 on metastasis of mouse osteosarcoma cells. Cancer Immunol Immunother 55: 1151-1158, 2006.

21. Xu T, Hao XS, Ren XB and Zhang HL: Killing effect of interleukin-18-enhanced FasL-expressing colon cancer cells on human hepatocytes in vitro. Zhonghua Zhong Liu Za Zhi 32: 659-662, 2010 (In Chinese).

22. Napetschnig $\mathrm{J}$ and $\mathrm{Wu} \mathrm{H}$ : Molecular basis of NF- $\mathrm{KB}$ signaling. Annu Rev Biophys 42: 443-468, 2013.

23. Karin M: Nuclear factor-kappaB in cancer development and progression. Nature 441: 431-436, 2006.

24. Slattery ML, Mullany LE, Sakoda L, Samowitz WS, Wolff RK, Stevens JR and Herrick JS: The NF-kB signalling pathway in colorectal cancer: Associations between dysregulated gene and miRNA expression. J Cancer Res Clin Oncol 144: 269-283, 2018.

25. Yang L, Zhou Y, Li Y, Zhou J, Wu Y, Cui Y, Yang G and Hong Y: Mutations of $\mathrm{p} 53$ and KRAS activate NF- $\kappa \mathrm{B}$ to promote chemoresistance and tumorigenesis via dysregulation of cell cycle and suppression of apoptosis in lung cancer cells. Cancer Lett 357: 520-526, 2015

26. Zeng Q, Li S, Zhou Y, Ou W, Cai X, Zhang L, Huang W, Huang L and Wang Q: Interleukin-32 contributes to invasion and metastasis of primary lung adenocarcinoma via NF-kappaB induced matrix metalloproteinases 2 and 9 expression. Cytokine 65: 24-32, 2014.

27. Zhang $\mathrm{H}$, Zhang $\mathrm{Z}$ and $\mathrm{Xu} \mathrm{Y}$ : Effects of interleukin-18 on asthmatic airway inflammation and nuclear factor kappa-B in murine models. Chin Med J (Engl) 116: 323-327, 2003

28. Kanda N, Shimizu T, Tada Y and Watanabe S: IL-18 enhances IFN-gamma-induced production of CXCL9, CXCL10, and CXCL11 in human keratinocytes. Eur J Immunol 37: 338-350, 2007.

29. Robertson MJ, Kirkwood JM, Logan TF, Koch KM, Kathman S, Kirby LC, Bell WN, Thurmond LM, Weisenbach J and Dar MM: A dose-escalation study of recombinant human interleukin-18 using two different schedules of administration in patients with cancer. Clin Cancer Res 14: 3462-3469, 2008.

30. Tarhini AA, Millward M, Mainwaring P, Kefford R, Logan T, Pavlick A, Kathman SJ, Laubscher KH, Dar MM and Kirkwood JM: A phase 2, randomized study of SB-485232, rhIL-18, in patients with previously untreated metastatic melanoma. Cancer 115: 859-868, 2009. 